\title{
A rare case of bilateral Killian-Jamieson diverticula treated endoscopically
}

A 68-year-old man presented with progressive dysphagia to solids and liquids, regurgitation of undigested food, and weight loss for the past three years. Upper gastrointestinal endoscopy followed by a barium esophagram revealed two contralateral diverticula in the cervical esophagus just below the cricopharyngeus. They measured $2 \mathrm{~cm}$ and $4 \mathrm{~cm}$ and were filled with food debris, consistent with two synchronous Killian-Jamieson diverticula ( Fig. 1). After multidisciplinary evaluation, endoscopic treatment was proposed.

The procedure was performed under general anesthesia with endotracheal intubation. A submucosal bleb was created proximal to the diverticula in the posterior wall, followed by a $1.5-\mathrm{cm}$ mucosal incision ( $\triangleright$ Video 1 ). A submucosal tunnel was created, which was then extended to both the end of the larger diverticulum and the proximal esophagus ( $\triangleright$ Fig. 2 ). Tunneling was continued until the bottom of the diverticulum was reached. The septum was thus entirely exposed and a complete septotomy was performed (>Fig.3, > Fig.4). Finally, the mucosal incision was closed using six clips. The procedure took 60 minutes and there were no complications.

The patient progressed well and a postprocedural barium esophagram confirmed the absence of any extraluminal oral contrast leak. At 4 months after the procedure, the patient remains asymptomatic on a regular diet.

A Killian-Jamieson diverticulum is an unusual form of esophageal diverticulum arising from a muscular gap in the anterolateral wall of the proximal cervical esophagus [1]. It can present with symptoms similar to those of a Zenker's diverticulum and presents anatomic challenges for any intervention, particularly owing to the high risk of injury to the recurrent laryngeal nerve [1]. Because of its rare incidence, treatment remains controversial [1]. Endoscopic therapies

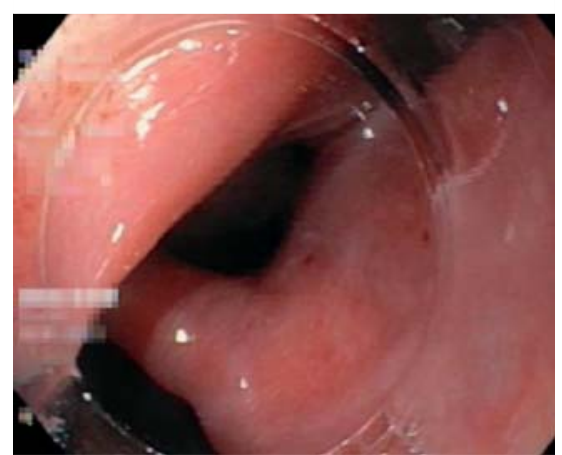

-Fig. 1 Endoscopic view of the two Killian-Jamieson diverticula.

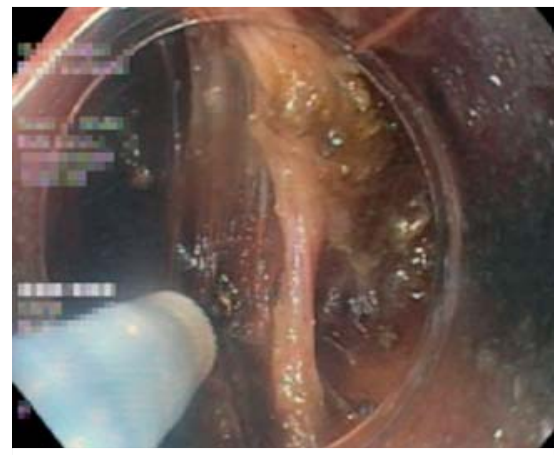

Fig. 3 Complete septotomy was performed.

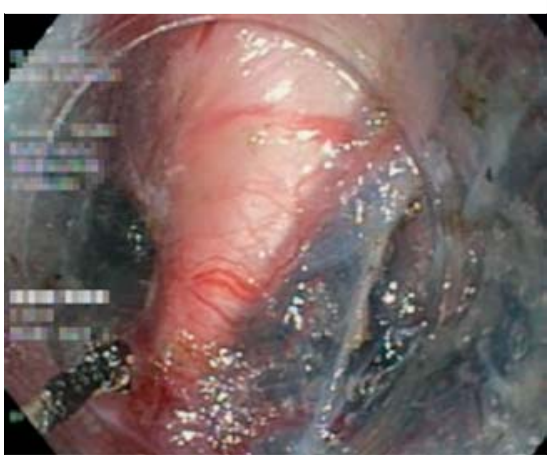

- Fig. 2 Tunneling was performed along both sides of the septum to allow septum isolation.

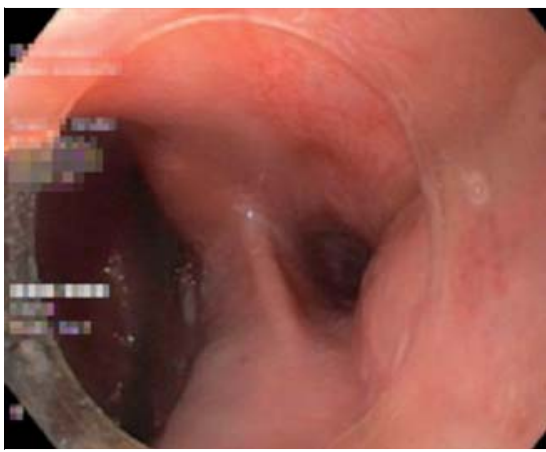

Fig. 4 Endoscopic view of the septum post-septotomy.

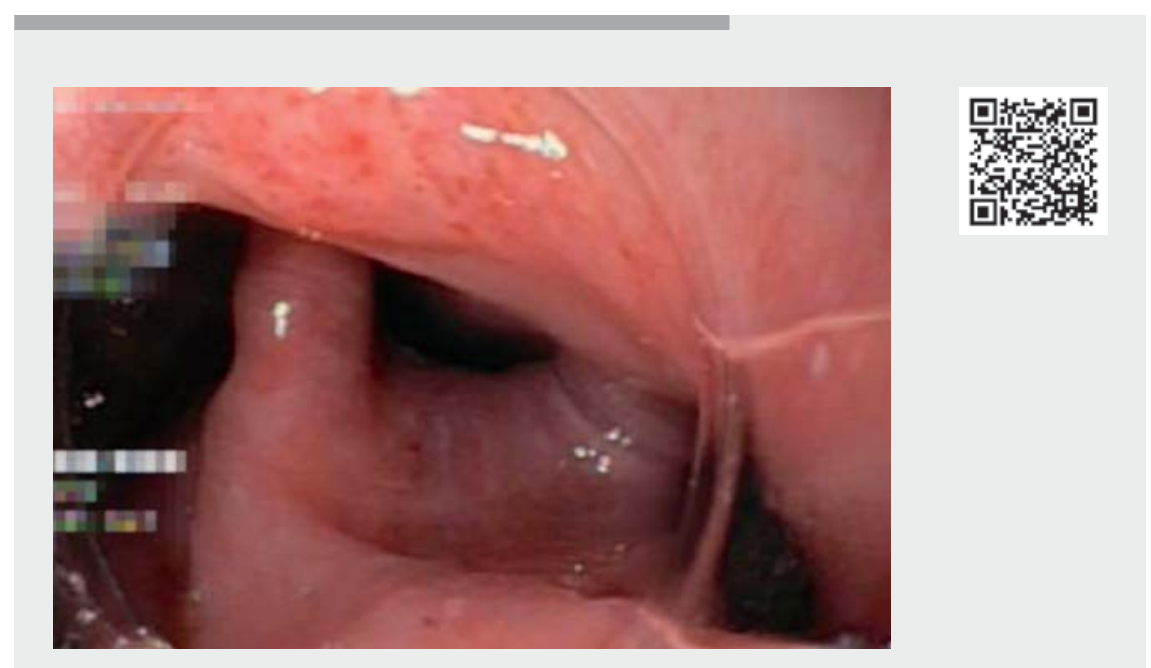

$\checkmark$ Video 1 Diverticular peroral endoscopic myotomy technique for the treatment of two Killian-Jamieson diverticula. 
have been reported as safe and effective [1-3]. To the best of our knowledge, this is the first case of the use of the peroral endoscopic myotomy technique for the treatment of two Killian-Jamieson diverticula.

Endoscopy_UCTN_Code_TTT_1AO_2AJ

\section{Competing interests}

The authors declare that they have no conflict of interest.

The authors

Catarina Félix 9 Pedro Barreiro, José Rodrigues, Rui Mendo $₫$, Catarina O’Neill $\odot$ Cristina Chagas

Gastroenterology Department, Centro Hospitalar Lisboa Ocidental EPE, Lisbon, Portugal
Corresponding author

\section{Catarina Félix, MD}

Centro Hospitalar Lisboa Ocidental EPE, Rua da Junqueira 126, 1349-019 Lisbon, Portugal

sfelixcatarina@gmail.com

\section{References}

[1] Saisho K, Matomo S, Akagi Y et al. Surgery for Killian-Jamieson diverticulum: a report of two cases. Surg Case Rep 2020; 6: 17

[2] Yang D, Draganov P. Endoscopic KillianJamieson diverticulotomy using a scissortype electrosurgical knife Endoscopy 2018; 50: E175-E176

[3] Miutescu B, Khan S, Khashab M et al. Role of peroral endoscopic myotomy (POEM) in the management of esophageal diverticula. Clin Endosc 2020; 53: 646-651
Bibliography

Endoscopy 2022; 54: E283-E284

DOI 10.1055/a-1517-6390

ISSN $0013-726 \mathrm{X}$

published online 2.7.2021

(c) 2021. Thieme. All rights reserved.

Georg Thieme Verlag KG, Rüdigerstraße 14,

70469 Stuttgart, Germany

\section{ENDOSCOPY E-VIDEOS \\ https://eref.thieme.de/e-videos}

口屌 Endoscopy E-Videos is an open access online section, 回: reporting on interesting cases and new techniques in gastroenterological endoscopy. All papers include a high quality video and all contributions are freely accessible online. Processing charges apply (currently EUR 375), discounts and wavers acc. to HINARI are available.

This section has its own submission website at

https://mc.manuscriptcentral.com/e-videos 